\title{
Safety of Routine Invasive Versus Selective Invasive Therapy in Women with Non-ST-Elevation Acute Coronary Syndrome
}

\author{
Anthony A. Bavry • Islam Y. Elgendy • Ahmed Mahmoud • \\ Manoj P. Jadhav · Tianyao Huo · Marian C. Limacher - Carl J. Pepine
}

To view enhanced content go to www.cardiologytherapy-open.com Received: October 3, 2015 / Published online: December 12, 2015

(C) The Author(s) 2015. This article is published with open access at Springerlink.com

\begin{abstract}
Introduction: Prior studies suggested that a routine invasive approach in the management of non-ST-elevation acute coronary syndrome (NSTE-ACS) is beneficial in men, but the data are less conclusive in women. One study conducted exclusively in women found that routine invasive therapy was associated with a markedly increased risk of major bleeding. This pilot randomized controlled trial compared the safety of a routine invasive versus a selective invasive strategy among women.
\end{abstract}

Methods: Women with NSTE-ACS and an additional high-risk characteristic were randomized to a routine invasive versus a selective invasive strategy. The primary outcome

Electronic supplementary material The online version of this article (doi:10.1007/s40119-015-0055-x) contains supplementary material, which is available to authorized users.

A. A. Bavry $(\square)$

North Florida/South Georgia Veterans Affairs Health

System, Gainesville, FL, USA

e-mail: bavryaa@medicine.ufl.edu;

anthony.bavry@va.gov

A. A. Bavry · I. Y. Elgendy · A. Mahmoud .

M. P. Jadhav · T. Huo · M. C. Limacher · C. J. Pepine

Department of Medicine, University of Florida,

Gainesville, FL, USA was the risk of major bleeding. The secondary outcome was the first occurrence of all-cause death, myocardial infarction, stroke, re-hospitalization for ACS, or major bleeding within 6 months.

Results: Twenty-three women were assigned to routine invasive therapy and 17 to selective invasive therapy. Twenty-seven women (68\%) had elevated troponin $\mathrm{T}$ (mean $0.33 \mathrm{ng} / \mathrm{mL}$ ) and/or creatinine kinase-MB (mean $23 \mathrm{ng} / \mathrm{mL}$ ). The risk of major bleeding was similar with both approaches $(P=0.99)$. At 6 months, the secondary outcome occurred in $9 \%$ of the routine invasive group versus $18 \%$ of the selective invasive group (risk ratio $=0.49$, 95\% confidence interval 0.09-2.63, $P=0.63$ ).

Conclusion: This pilot study demonstrated that a routine invasive approach is safe in women. There was suggestion of benefit from routine invasive therapy compared with selective invasive therapy. These data could be used to design an appropriately powered trial to determine the optimal management strategy among women with NSTE-ACS.

Keywords: Major bleeding; Myocardial infarction; Non-ST-elevation acute coronary syndrome; Sex differences; Women 


\section{INTRODUCTION}

The efficacy and safety of routine invasive versus selective invasive therapy may not apply similarly to women and men with non-ST-elevation acute coronary syndrome (NSTE-ACS). Meta-analyses have documented a reduction in death or myocardial infarction among NSTE-ACS men that undergo routine invasive therapy $[1,2]$. However, benefit has been more difficult to detect among NSTE-ACS women who undergo routine invasive therapy. In addition to bleeding differences [3], women appear to be more likely to present with normal or less severe coronary artery disease $[4,5]$. The only randomized trial conducted exclusively in women comparing both approaches documented a non-significant increase in death or myocardial infarction among invasively treated women. In fact, invasive therapy was associated with excess mortality at 1 year [6]. In that study, the risk of major bleeding was approximately $9 \%$ at 30 days in the routine invasive arm. The patients were treated with either low molecular weight heparin or fondaparinux, which could have contributed to the increased bleeding $[7,8]$. The aim of this study was to compare the safety of routine invasive versus conservative strategies in women who are treated with contemporary medical therapy for NSTE-ACS and to determine the adequate sample size for a randomized clinical trial should this approach appear to be safe.

\section{METHODS}

Women at least 18 years of age with NSTE-ACS (defined as new-onset chest discomfort at rest or with low levels of activity/or emotion within the preceding $48 \mathrm{~h}$ ) were eligible if they had an elevated cardiac enzyme (troponin $T \geq 0.03 \mathrm{ng} / \mathrm{mL}$ or creatinine kinase-MB isoenzyme $\geq 5.0 \mathrm{ng} / \mathrm{mL}$ ). Troponin $\mathrm{T}$ was measured by electrochemiluminescence using the Roche Elecsys analyzer, and creatinine kinase-MB was measured by immunoassay using the Roche Cobas analyzer (Roche, Basel, Switzerland). Subjects without elevation in cardiac enzymes were considered eligible if they had an elevated NT-pro-brain natriuretic peptide (NT-proBNP; $\geq 450 \mathrm{pg} / \mathrm{mL}), \quad$ ST-segment depression $(\geq 0.5 \mathrm{~mm})$, or thrombolysis in myocardial infarction (TIMI) risk score $>2$. Exclusion criteria included ST-elevation myocardial infarction, cardiogenic shock, congestive heart failure, hemodynamic instability, use of fibrinolytic therapy in the last $96 \mathrm{~h}$, current bleeding or bleeding disorder within the last 3 months that required transfusion, pregnancy, contraindication to any study medication (heparin, clopidogrel, or glycoprotein IIb/III inhibitor), percutaneous coronary intervention in the last 6 months, or inability to provide written informed consent.

The study protocol was approved by the University of Florida Institutional Review Board. All procedures followed were in accordance with the ethical standards of the responsible committee on human experimentation (institutional and national) and with the Helsinki Declaration of 1964, as revised in 2013. Informed consent was obtained from all patients for being included in the study.

Women who provided written informed consent were randomly assigned to a routine invasive versus a selective invasive strategy. Treatment assignment was performed by opening a sealed opaque envelope. The routine invasive group was recommended to undergo coronary angiography within $48 \mathrm{~h}$ of hospital admission. Cardiac catheterization was recommended in the selective invasive 
group for refractory chest pain, hemodynamic/electrical instability, left ventricular systolic dysfunction, or an abnormal myocardial perfusion stress test; however, patient management decisions were ultimately left to treating physician.

The primary outcome was the risk of major bleeding. Major bleeding was defined as significantly disabling intra-cranial or intra-ocular bleeding, bleeding that required intervention or transfusion, or at least $5 \mathrm{~g} / \mathrm{dL}$ drop in hemoglobin. The secondary outcome was the first occurrence of all-cause death, myocardial infarction, stroke, re-hospitalization for ACS, or major bleeding within 6 months. Myocardial infarction was defined as an elevation in creatine kinase-MB isoenzyme greater than the upper limit of normal which occurred spontaneously or in the setting of percutaneous coronary intervention. Myocardial infarction in the setting of coronary artery bypass grafting required the presence of new Q-waves $[9,10]$. Urgent hospitalization was defined as the need for hospitalization due to an ACS (ST-elevation, non-ST-elevation, or unstable angina) regardless of the treatment delivered (e.g., urgent revascularization versus conservative therapy). Stroke was defined as an ischemic event that caused disabling neurological symptoms that are present for more than $24 \mathrm{~h}$. Urgent target vessel revascularization was defined as recurrent ischemic symptoms that resulted in the need for repeat percutaneous intervention or surgical revascularization. Risk ratio (RR) with 95\% confidence interval (CI) for the outcomes was reported. Survival analyses were performed using the Kaplan-Meier method, and the log-rank test was used to compare differences of event-free survival between the two arms. All analyses were performed using SAS 9.3 (SAS Institute, Cary, NC, USA).

\section{RESULTS}

Twenty-three women were assigned to routine invasive therapy and 17 to selective invasive therapy. All women had 6-month follow-up (24 women followed to 12 months and 13 women to 24 months). Figure 1 summarizes the study flow diagram. Women were $60 \pm 13$ years of age, $25 \%$ had diabetes, $43 \%$ were current smokers, and $68 \%$ had a history of hypertension (Table 1). The majority of women received aspirin (98\%), beta blockers (88\%), and statins (80\%). Twenty-seven women (68\%) had elevated troponin $\mathrm{T}$ (mean $0.33 \mathrm{ng} / \mathrm{mL}$ ) and/or creatinine kinase-MB (mean $23 \mathrm{ng} / \mathrm{mL}$ ).

One woman randomized to routine invasive therapy subsequently refused catheterization. In this group, the mean time from randomization to catheterization was $11.7 \pm 23.2 \mathrm{~h}$. In the routine invasive group, three women underwent successful percutaneous coronary intervention, while in three women a chronic occlusion was unable to be re-vascularized. In the selective invasive strategy group, catheterization was performed for electrical/hemodynamic instability $(n=4)$, low ejection fraction $(n=3)$, abnormal stress test $(n=2)$, and refractory chest pain $(n=1)$. In the selective invasive group, two women underwent successful percutaneous coronary intervention. Except for one patient in the routine invasive group, catheterization was exclusively performed by femoral artery access.

Only one patient in the routine invasive therapy encountered major bleeding. At 6 months, the composite outcome (intention-to-treat) occurred in $9 \%$ of the routine invasive group versus $18 \%$ of the selective invasive group ( $\mathrm{RR}=0.49,95 \%$ CI $0.09-2.63, P=0.63)$. Additional outcomes are provided in Table 2. At a mean follow-up of 12.5 months, there was a non-significant 


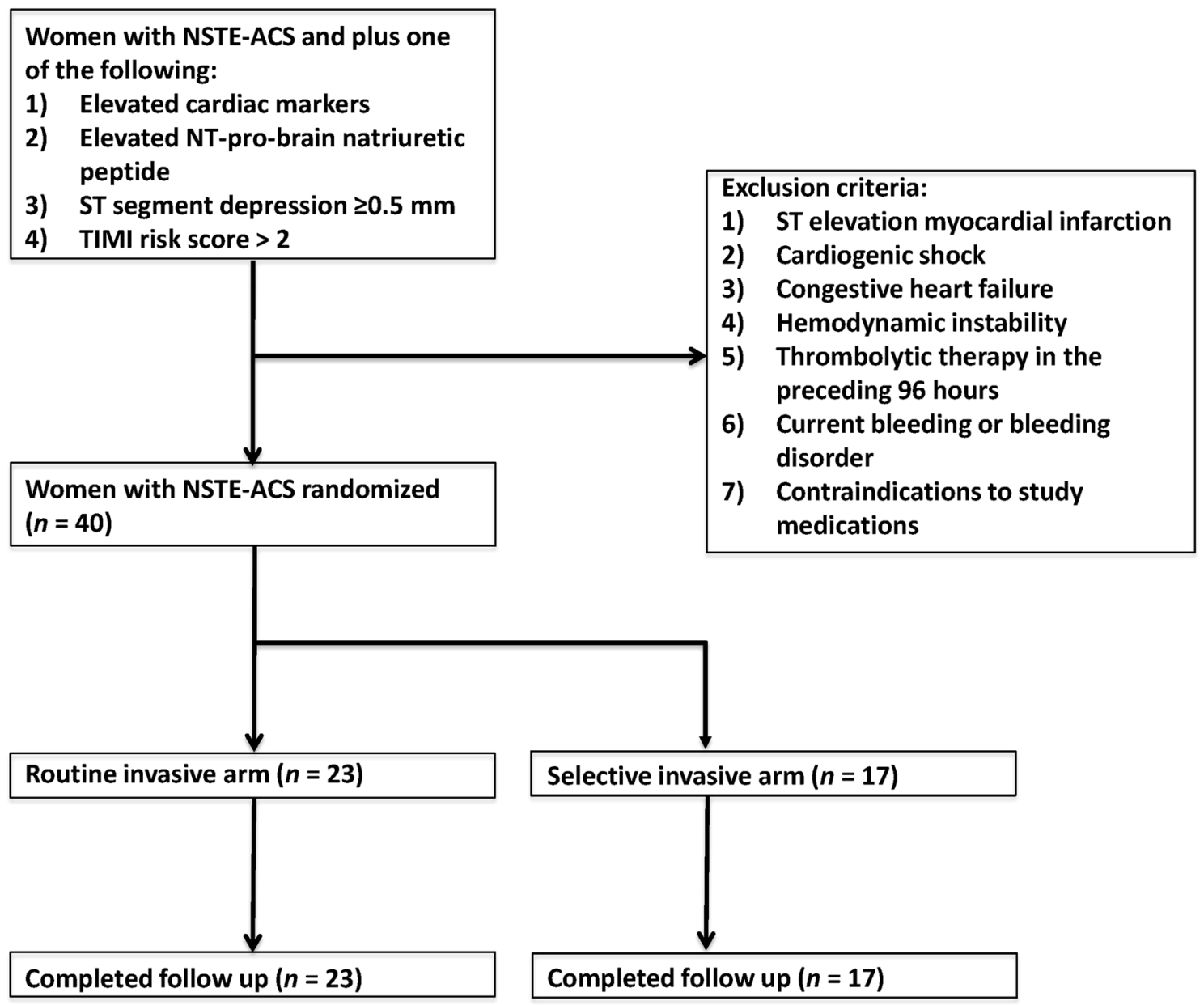

Fig. 1 Study flow diagram. NSTE-ACS non-ST-elevation acute coronary syndrome, TIMI thrombolysis in myocardial infarction

benefit favoring routine invasive therapy (log-rank $P=0.11)$.

\section{DISCUSSION}

Among women with NSTE-ACS, a routine invasive therapy appeared to be safe with no signal for an increase in major bleeding. Although not powered for clinical outcomes, there were numerically fewer adverse cardiovascular events among the routine invasive therapy group. The control arm of our study received selective invasive therapy, which is distinct from conservative therapy.
Accordingly, patients underwent monitoring and additional risk stratification during their hospitalization. As a result, many patients crossed over to invasive therapy. However, we do not consider these crossovers to be a limitation, but rather a reality of clinical care.

Although prior meta-analyses had demonstrated the benefits of a routine invasive approach $[11,12]$, it is important to emphasis that NSTE-ACS clinical trials have shown a remarkable degree of sex bias. In a pooled analysis of ACS trials, women comprised only $25 \%$ of the patient population [13]. Furthermore, evidence had shown that 
Table 1 Baseline characteristics of the study cohort

\begin{tabular}{|c|c|c|c|c|}
\hline Characteristics & Total $(n=40)$ & $\begin{array}{l}\text { Routine invasive } \\
(n=23)\end{array}$ & $\begin{array}{l}\text { Selective invasive } \\
(n=17)\end{array}$ & $P$ value \\
\hline Age, years $($ mean $\pm S D)$ & $60 \pm 13$ & $58 \pm 15$ & $62 \pm 10$ & 0.30 \\
\hline $\begin{array}{l}\text { Body mass index, } \mathrm{kg} / \mathrm{m}^{2} \\
\quad(\text { mean } \pm \mathrm{SD})\end{array}$ & $28 \pm 9$ & $30 \pm 9$ & $26 \pm 9$ & 0.19 \\
\hline \multicolumn{5}{|l|}{ History of $[n(\%)]$} \\
\hline Diabetes & $10(25)$ & $5(22)$ & $5(29)$ & 0.72 \\
\hline Current smoking & $17(43)$ & $10(43)$ & $7(41)$ & $>0.99$ \\
\hline Hypertension & $27(68)$ & $14(61)$ & $13(76)$ & 0.33 \\
\hline Hypercholesterolemia & $21(53)$ & $14(61)$ & $7(41)$ & 0.34 \\
\hline Myocardial infarction & $7(18)$ & $6(26)$ & $1(6)$ & 0.21 \\
\hline Stroke/transient ischemic attack & $6(15)$ & $5(22)$ & $1(6)$ & 0.20 \\
\hline $\begin{array}{l}\text { Percutaneous coronary } \\
\text { intervention }\end{array}$ & $8(20)$ & $7(30)$ & $1(6)$ & \\
\hline Coronary artery bypass grafting & $2(5)$ & $2(9)$ & $0(0)$ & 0.50 \\
\hline \multicolumn{5}{|c|}{ Medications at randomization $[n(\%)]$} \\
\hline Aspirin & $39(98)$ & $22(96)$ & $17(100)$ & $>0.99$ \\
\hline Clopidogrel & $26(65)$ & $14(61)$ & $12(71)$ & 0.74 \\
\hline ACE inhibitor/ARB & $33(83)$ & $18(78)$ & $15(88)$ & $>0.99$ \\
\hline Beta blocker & $35(88)$ & $20(87)$ & $15(88)$ & $>0.99$ \\
\hline Statin & $32(80)$ & $19(83)$ & $13(76)$ & 0.70 \\
\hline Insulin & $7(18)$ & $3(13)$ & $4(24)$ & 0.43 \\
\hline \multicolumn{5}{|l|}{ Laboratory data (mean $\pm S D)$} \\
\hline Total cholesterol, mg/dL & $179 \pm 46(n=30)$ & $173 \pm 39(n=18)$ & $188 \pm 55(n=12)$ & 0.40 \\
\hline Triglycerides, $\mathrm{mg} / \mathrm{dL}$ & $164 \pm 102(n=30)$ & $170 \pm 104(n=18)$ & $154 \pm 103(n=12)$ & 0.66 \\
\hline HDL cholesterol, mg/dL & $47 \pm 16(n=30)$ & $48 \pm 16(n=18)$ & $47 \pm 16(n=13)$ & 0.86 \\
\hline LDL cholesterol, mg/dL & $113 \pm 77(n=29)$ & $115 \pm 93(n=18)$ & $110 \pm 44(n=12)$ & 0.87 \\
\hline CK-MB, ng/mL ${ }^{a}$ & $23 \pm 19(n=19)$ & $25 \pm 20(n=9)$ & $21 \pm 18(n=10)$ & 0.67 \\
\hline Troponin $\mathrm{T}, \mathrm{ng} / \mathrm{mL}^{\mathrm{a}}$ & $\begin{array}{c}0.33 \pm 0.44 \\
(n=25)\end{array}$ & $0.38 \pm 0.60(n=12)$ & $0.29 \pm 0.20(n=13)$ & 0.62 \\
\hline NT-proBNP, pg/mL ${ }^{\mathrm{a}}$ & $\begin{array}{c}4636 \pm 4775 \\
(n=8)\end{array}$ & $3913 \pm 3716(n=5)$ & $5841 \pm 6980(n=3)$ & 0.62 \\
\hline \multicolumn{5}{|l|}{ Risk scores } \\
\hline TIMI $^{\mathrm{b}}$ & $3 \pm 1$ & $3 \pm 1.4$ & $3 \pm 1.6$ & 0.45 \\
\hline GRACE $^{\mathrm{b}}$ & $103 \pm 29$ & $98 \pm 31$ & $110 \pm 27$ & 0.21 \\
\hline
\end{tabular}


Table 1 continued

\begin{tabular}{lccc}
\hline Characteristics & Total $(\boldsymbol{n}=\mathbf{4 0})$ & $\begin{array}{l}\text { Routine invasive } \\
(\boldsymbol{n}=\mathbf{2 3})\end{array}$ & $\begin{array}{l}\text { Selective invasive } \\
(\boldsymbol{n}=\mathbf{1 7})\end{array}$ \\
\hline HAS-BLED ${ }^{\mathrm{b}}$ & $1 \pm 1$ & $1 \pm 0.99$ & $1 \pm 0.94$ \\
\hline$A C E$ angiotensin converting enzyme, $A R B$ angiotensin receptor blocker, $C K-M B$ & creatine kinase-myocardial band, $H D L$ \\
high-density lipoprotein, $L D L$ low-density lipoprotein, $N T$-proBNP N-terminal-pro brain natriuretic peptide, $S D$ standard \\
deviation \\
a Means obtained among those with CK-MB $\geq 5.0 \mathrm{ng} / \mathrm{mL}$, troponin $T \geq 0.03 \mathrm{ng} / \mathrm{mL}$, and NT-proBNP $\geq 450 \mathrm{pg} / \mathrm{mL} \mathrm{for}$ \\
$\begin{array}{l}\text { each category } \\
\mathrm{b} \text { Median was reported }\end{array}$
\end{tabular}

Table 2 Six-month outcomes

\begin{tabular}{llll}
\hline & $\begin{array}{l}\text { Routine invasive } \\
(n=23) n(\%)\end{array}$ & $\begin{array}{l}\text { Selective invasive } \\
(\boldsymbol{n}=\mathbf{1 7}) \boldsymbol{n}(\%)\end{array}$ \\
\hline Composite outcome $^{\mathrm{a}}$ & & \\
Intention to treat & $2(9)$ & $3(18)$ & 0.63 \\
Actual treatment received & $2(9)$ & $4(24)$ & 0.26 \\
Other outcomes & & $1(6)^{\mathrm{b}}$ & - \\
Death & $0(0)$ & $0(0)$ & 0.43 \\
MI & $0(0)$ & $1(6)$ & 0.43 \\
Stroke & $0(0)$ & $2(12)$ & 0.56 \\
Urgent hospitalization for ACS & $1(4)$ & $0(0)$ & 0.99 \\
Major bleeding & $1(4)$ & $3(18)$ \\
Death, MI, stroke, re-hospitalization for ACS & $1(4)$ & 0.29 \\
\hline
\end{tabular}

$A C S$ acute coronary syndrome, $M I$ myocardial infarction

a Death, MI, re-hospitalization for ACS, stroke, or major bleeding

b Death occurred in a patient with acute lymphoblastic leukemia

bleeding events are higher in women undergoing percutaneous coronary interventions compared with men $[14,15]$. Therefore, this pilot study aimed to address the question whether a routine invasive approach would be safe. Although the OASIS-5 sub-study had addressed this same question, the bleeding events in that study were remarkably high which could have been attributed to the study design [6].
Although we attempted to enroll high-risk women, the proportion of women who underwent revascularization was low (i.e., $<20 \%$ ). Approximately one-fifth of women had a chronic total occlusion, which is similar to previous findings [16]. While $68 \%$ of our study participants were eligible due to elevated cardiac enzymes, the remainder met other eligibility characteristics which might not adequately risk-stratified patients. However, 
the median TIMI risk score was 3 and in the TACTICS-TIMI 18 trial, intermediate- to high-risk patients (score $\geq 3$ ) benefited from invasive therapy [17]. Current guidelines recommend routine invasive therapy for high-risk women (i.e., elevated troponin); however, routine invasive therapy is less favorable in low-risk NSTE-ACS women [18]. Based on our observed 6-month event rate of $18 \%$ in the selective invasive arm, we estimate that 3454 patients would be needed to detect a $20 \%$ relative difference between treatment arms with $80 \%$ power.

\section{CONCLUSION}

This study demonstrates that a routine invasive approach is safe in women. There was suggestion of benefit from routine invasive therapy compared with selective invasive therapy. These data could be used to design an appropriately powered trial to determine the optimal management strategy among women with NSTE-ACS.

\section{ACKNOWLEDGMENTS}

The Lady Gator pilot study was supported by Gatorade Research Funds, University of Florida Department of Medicine, Gainesville, FL, USA. All named authors meet the International Committee of Medical Journal Editors (ICMJE) criteria for authorship for this manuscript, take responsibility for the integrity of the work as a whole, and have given final approval for the version to be published.

Disclosures. Anthony A. Bavry, Islam Y. Elgendy, Ahmed Mahmoud, Manoj P. Jadhav, Tianyao Huo, Marian C. Limacher, and Carl J. Pepine have nothing to disclose.
Compliance with Ethics Guidelines. All procedures followed were in accordance with the ethical standards of the responsible committee on human experimentation (institutional and national) and with the Helsinki Declaration of 1964, as revised in 2013. Informed consent was obtained from all patients for being included in the study.

Open Access. This article is distributed under the terms of the Creative Commons Attribution-NonCommercial 4.0 International License (http://creativecommons.org/licenses/ by-nc/4.0/), which permits any noncommercial use, distribution, and reproduction in any medium, provided you give appropriate credit to the original author(s) and the source, provide a link to the Creative Commons license, and indicate if changes were made.

\section{REFERENCES}

1. Bavry AA, Kumbhani DJ, Quiroz R, Ramchandani SR, Kenchaiah S, Antman EM. Invasive therapy along with glycoprotein IIb/IIIa inhibitors and intracoronary stents improves survival in non-ST-segment elevation acute coronary syndromes: a meta-analysis and review of the literature. Am J Cardiol. 2004;93:830-5.

2. Alfredsson J, Clayton T, Damman P, et al. Impact of an invasive strategy on 5 years outcome in men and women with non-ST-segment elevation acute coronary syndromes. Am Heart J. 2014;168:522-9.

3. Alexander KP, Chen AY, Newby LK, et al. Sex differences in major bleeding with glycoprotein IIb/ IIIa inhibitors: results from the CRUSADE (Can Rapid risk stratification of Unstable angina patients Suppress ADverse outcomes with Early implementation of the ACC/AHA guidelines) initiative. Circulation. 2006;114:1380-7.

4. Glaser R, Herrmann HC, Murphy SA, et al. Benefit of an early invasive management strategy in women with acute coronary syndromes. JAMA. 2002;288:3124-9.

5. Lagerqvist B, Safstrom K, Stahle E, Wallentin L, Swahn E. Is early invasive treatment of 
unstable coronary artery disease equally effective for both women and men? FRISC II Study Group Investigators. J Am Coll Cardiol. 2001;38:41-8.

6. Swahn E, Alfredsson J, Afzal R, et al. Early invasive compared with a selective invasive strategy in women with non-ST-elevation acute coronary syndromes: a substudy of the OASIS 5 trial and a meta-analysis of previous randomized trials. Eur Heart J. 2012;33:51-60.

7. Ferguson JJ, Califf RM, Antman EM, et al. Enoxaparin vs unfractionated heparin in high-risk patients with non-ST-segment elevation acute coronary syndromes managed with an intended early invasive strategy: primary results of the SYNERGY randomized trial. JAMA. 2004;292:45-54.

8. Murphy SA, Gibson CM, Morrow DA, et al. Efficacy and safety of the low-molecular weight heparin enoxaparin compared with unfractionated heparin across the acute coronary syndrome spectrum: a meta-analysis. Eur Heart J. 2007;28:2077-86.

9. de Winter RJ, Windhausen F, Cornel JH, et al. Early invasive versus selectively invasive management for acute coronary syndromes. $\mathrm{N}$ Engl J Med. 2005;353:1095-104.

10. Fox KA, Poole-Wilson PA, Henderson RA, et al. Interventional versus conservative treatment for patients with unstable angina or non-ST-elevation myocardial infarction: the British Heart Foundation RITA 3 randomised trial. Randomized Intervention Trial of unstable Angina. Lancet. 2002;360:743-51.

11. Mehta SR, Cannon CP, Fox KA, et al. Routine vs selective invasive strategies in patients with acute coronary syndromes: a collaborative meta-analysis of randomized trials. JAMA. 2005;293:2908-17.

12. Bavry AA, Kumbhani DJ, Rassi AN, Bhatt DL, Askari AT. Benefit of early invasive therapy in acute coronary syndromes: a meta-analysis of contemporary randomized clinical trials. J Am Coll Cardiol. 2006;48:1319-25.

13. Melloni C, Berger JS, Wang TY, et al. Representation of women in randomized clinical trials of cardiovascular disease prevention. Circ Cardiovasc Qual Outcomes. 2010;3:135-42.

14. Daugherty SL, Thompson LE, Kim S, et al. Patterns of use and comparative effectiveness of bleeding avoidance strategies in men and women following percutaneous coronary interventions: an observational study from the National Cardiovascular Data Registry. J Am Coll Cardiol. 2013;61:2070-8.

15. Ahmed B, Piper WD, Malenka D, et al. Significantly improved vascular complications among women undergoing percutaneous coronary intervention: a report from the Northern New England Percutaneous Coronary Intervention Registry. Circ Cardiovasc Interv. 2009;2:423-9.

16. Christofferson RD, Lehmann KG, Martin GV, Every N, Caldwell JH, Kapadia SR. Effect of chronic total coronary occlusion on treatment strategy. Am J Cardiol. 2005;95:1088-91.

17. Cannon CP, Weintraub WS, Demopoulos LA, et al. Comparison of early invasive and conservative strategies in patients with unstable coronary syndromes treated with the glycoprotein IIb/IIIa inhibitor tirofiban. N Engl J Med. 2001;344: 1879-87.

18. Amsterdam EA, Wenger NK, Brindis RG, et al. 2014 AHA/ACC guideline for the management of patients with non-ST-elevation acute coronary syndromes: a report of the American College of Cardiology/American Heart Association Task Force on Practice Guidelines. Circulation. 2014;130: e344-426. 